\title{
Multiple-Mixing-Cell Model for Calculation of Minimum Miscibility Pressure Controlled by Tie-Line Length
}

\author{
FuLin Yang $\mathbb{D}$, Peng Yu $\mathbb{D}$, and Xue Zhang \\ College of Petroleum and Chemical Engineering, Beibu Gulf University, Qinzhou, Guangxi 535011, China \\ Correspondence should be addressed to Peng Yu; developoil@163.com
}

Received 24 December 2019; Accepted 11 February 2020; Published 6 March 2020

Guest Editor: Hui Pu

Copyright (c) 2020 FuLin Yang et al. This is an open access article distributed under the Creative Commons Attribution License, which permits unrestricted use, distribution, and reproduction in any medium, provided the original work is properly cited.

\begin{abstract}
A simple and robust algorithm has been developed to calculate the minimum miscibility pressure (MMP), which is considered one of the crucial and essential design parameters of miscible gas injection projects for enhanced oil recovery (EOR). This algorithm is to track all tie-line lengths through the cell-cell calculation by the minimum distance function for the prediction of MMP. The MMP is the pressure at which any one of all key tie-line lengths becomes zero. To verify the accuracy of the revised MMC algorithm for determining MMP, several examples taken from the published literature have been examined. The calculation results of our revised MMC algorithm show excellent agreement with those estimated by MOC, MMC, and slim-tube experiments, which are found to be reliable within acceptable accuracy (4.53\%-0.50\%).
\end{abstract}

\section{Introduction}

$\mathrm{CO}_{2}$ miscible flooding has become a technique that is used most extensively to enhance oil recovery [1-3]. In recent years, $\mathrm{CO}_{2}$ flooding has attracted increasing global attention and research interest, due to improving the oil recovery rate of depleted reservoirs and eliminating greenhouse gas emission $[4,5]$. When designing any one of $\mathrm{CO}_{2}$ miscible gas flooding projects, the minimum miscible pressure (MMP) is one of the crucial and essential parameter to achieve the maximum oil production as well as to evaluate the miscibility between injection gas and reservoir fluids. At the MMP, it theoretically can achieve $100 \%$ local oil recovery from the reservoir [6], which leads to a huge economic income. Therefore, an inaccurate MMP prediction may lead to the high cost of the injection process or low oil recovery rate. According to published literature, numerous experimental methods, empirical correlations, and computational methods have been developed for determining the MMPs between different injected gas and reservoir fluids under various conditions. Among them, the experimental method for measuring the MMP mainly consists of the slim-tube test, multiple contact method (MCM), vanishing interfacial tension (VIT) method, and rising bubble apparatus (RBA) method [7-11]. The slimtube test is usually applied to measure the MMP in the oil industry as a standard method since it can reproduce the complicated interactions of fluid flow and phase behavior in porous media. However, this method can be high cost and time-consuming; this means that it will spend 4 to 6 weeks on the MMP measurement of a given oil-gas system. This method also requires a large number of experimental works. Besides the slim-tube method, the MCM can provide an accurate MMP when the miscible displacement is vaporizing or condensing drives which usually occur less frequently. Other experimental MMP methods, such as RBA and VIT, cannot obtain reliable predictions of the MMP because they may not capture the complex interactions between fluid flow and its phase behavior for the miscibility of most field gas floods, which are both condensing/vaporizing (CV) drives. In addition to experimental methods, empirical correlations are proposed from statistically analyzing experimental data based on tuning and calibration and therefore can obtain the accuracy prediction of MMPs for specific oil-gas systems [12]. A slight change in the reservoir condition arises a huge error in the MMPs estimated by these correlations. 
Because of the drawbacks of both experimental and empirical methods, many efforts over the years are made to develop calculated methods for MMP determined by the equation of state (EOS). The calculated methods for determining MMP are cheaper and also faster than the aforementioned methods. Three main calculated methods for determining the MMP are the $1 \mathrm{D}$ slim-tube compositional simulation, the method of characteristics (MOC), and the multiple-mixing-cell (MMC) method [13]. As a matter of fact, the 1D slim-tube compositional simulation mimics the fluid flow in slim-tube experiments to determine the MMP. As described in the slim-tube experiments, the MMP can be estimated by a "knee" in the recovery curve. This method, however, can be influenced by the numerical dispersion, causing the inaccuracy prediction of the MMP. To obtain a better accurate MMP, the simulations are repeated under various levels of dispersion (different grid block sizes), and then, the predicted MMP is extrapolated to zero dispersion $[14,15]$. Therefore, this method is more troublesome and time-consuming than other calculated methods because multiple simulations with various grid block sizes must be made at different pressures. According to the analytical solution of the dispersion-free 1D flow equations, the MOC approach has been developed [16-20]. As pointed out by Johns and Orr [18], for $n_{c}$ number of components, the development of miscibility in gas floods is controlled by a sequence of $n_{\mathrm{c}}-1$ key tie lines. So, the MMP is the pressure where any one of all key tie lines intersects a critical point (becomes zero length). However, the MOC method is complicated and can easily converge to a series of wrong key tie lines for multicomponent-injected gases, as described by Yuan and Johns [20]. Besides, the MOC algorithm has a potential issue of flash calculation as pointed out by Ahmadi et al. [13, 21, 22], and the estimated MMP has a huge error under bifurcation conditions.

There are many published MMC approaches for estimating the MMP. However, researchers have considered mainly two MMC methods [21-25]. The first MMC method is proposed by Ahmadi et al. [21, 22]. In this method, the calculations firstly start from two cells at a fixed pressure and temperature, which are filled by injected gas and reservoir fluid. And then, two equilibrium compositions, liquid mole fraction $x$ and vapor mole fraction $y$, are obtained after $P / T$ flash calculation. Assuming the equilibrium vapor phase $(y)$ always moves before the equilibrium liquid phase $(x)$, the calculations perform cell-to-cell contacts between resulting equilibrium compositions. Several contacts continue through using $P / T$ flash calculation until all key tie lines of the displacement are captured to the desired accuracy and the minimum key tie line is stored. This procedure is then repeated by increasing the pressure. As in the MOC method [16-20], the MMP is determined when the minimum key tie line intersects a critical point (or becomes zero length). The advantage of this approach is independent of phase mobilities (fractional flow) and automatically converges a unique set of key tie lines after sufficient contacts. Moreover, the MMC method is recently applied to the displacement of three-hydrocarbon-phase oil by pure $\mathrm{CO}_{2}$ considering the asphaltene-precipitation effect on MMPs at low temperatures [26].
Another method is developed by Jaubert et al. [24, 25], which is similar to the one proposed by Metcalfe et al. [23]. In the second method, the $1 \mathrm{D}$ slim-tube composition simulation is simplified by ignoring flow equations. Firstly, a packed slim tube is discretized into several cells with a fixed volume, which are filled by initially reservoir oil. And then, a certain amount of gas is injected to cell 1; assuming perfect mixing, after $P / T$ flash calculation for mixture in the cell 1 under the given pressure and temperature condition, the excess volume than the cell volume will be added to cell 2 and mixed with the fluid in the cell 2. The process continues from cell to cell until a certain volume of injected gas is implemented (typically 1.2 times the slim-tube total volume). To reduce the numerical dispersion effect, under a given pressure, recovery factors at 1.2 porous volume (PV) of slim tube are obtained for different numbers of cells. The relationship of the oil recovery rate versus $1 / \sqrt{N_{c}}$, where $N_{c}$ is the number of cells, is extrapolated to obtain the predicted dispersion-free oil recovery rate for the pressure. And then, a plot of the predicted oil recovery rate at zero dispersion is given out for several pressures, the MMP is estimated by extrapolating to a near $100 \%$ oil recovery rate. Zhao et al. proposed a more complex MMC method [27, 28], which uses the fractional flow function to transfer the excess volume from one cell to the next cell. However, this is difficult to evaluate because there are no calculated examples of the MMP given in their work. Therefore, it is necessary to give some MMP calculation examples for evaluation of the method and also improve the robustness and computable speed of their MMC method.

In this study, we proposed a new MMC model for estimating the MMP, which tracks all tie-line lengths through the cell-cell calculation by the minimum distance function. In fact, this algorithm is to track all tie-line lengths by modifying the MMC method developed by Zhao et al. for the estimation of MMP $[27,28]$. In the first section, our MMC algorithm was described in detail, and it was shown that a series of all $n_{c}-1$ key tie lines [16-20] are captured to the desired accuracy, which are the initial tie line, the injection tie line, and $\left(n_{c}-3\right)$ crossover tie lines. And then, the MMP is determined by tracking any one of all key tie lines becoming zero length (or intersecting a critical point). In the second section, several examples are taken from the published literature, and the MMPs predicted by our algorithm are compared to calculation results of MOC and MMC and measurement results of slim-tube experiments, indicating excellent agreement.

\section{Algorithms and Methods}

2.1. Modified Multiple-Mixing-Cell Model. A miscibility process of gas injection is controlled by a series of $\left(n_{c}-1\right)$ key tie lines: the initial or oil tie line, the injection or gas tie line, and $\left(n_{c}-3\right)$ crossover tie lines, in which $n_{c}$ is the number of components [16-20]. The MMP is the pressure at which any one of all key tie lines intersects a critical point (becomes zero length). As pointed out in the published literature, the tie-line length (TL) can robustly be used to 


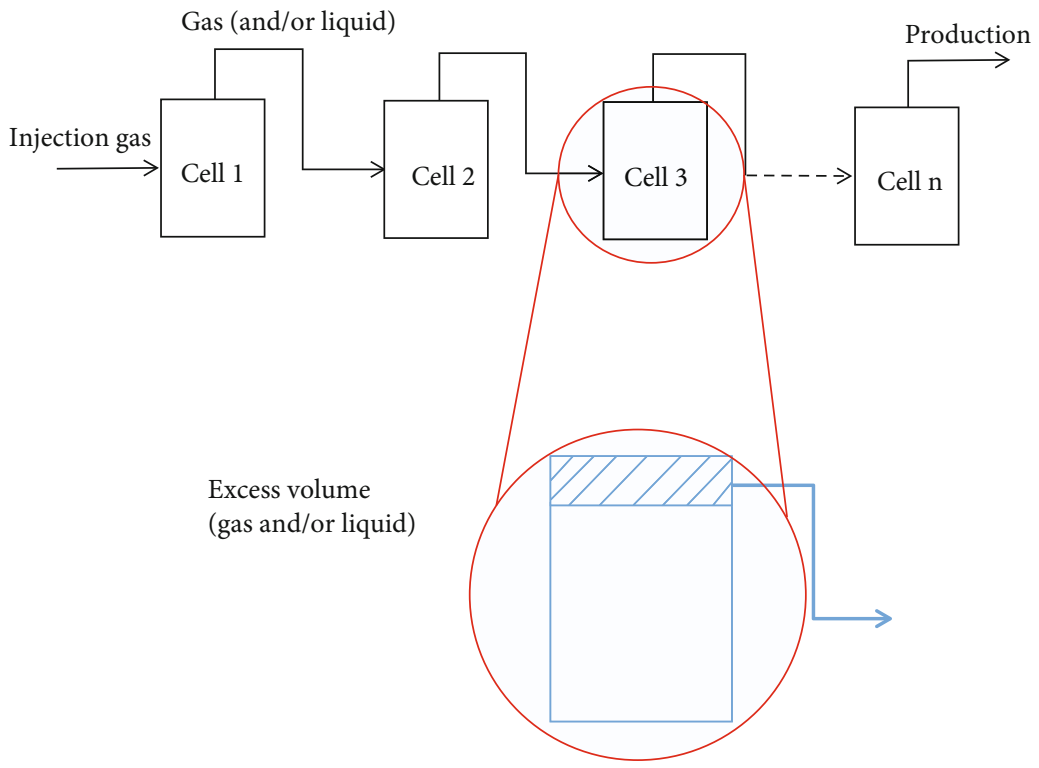

FIgURE 1: Schematic diagram of the MMC model.

estimate the MMP. The TL can be calculated by the equation as follows:

$$
\mathrm{TL}=\sqrt{\sum_{i}\left(x_{i}-y_{i}\right)^{2}}
$$

where $x_{i}$ and $y_{i}$ are the liquid and vapor equilibrium mole fractions, respectively.

In the MMC model, a packed slim tube and a continuous gas injection process are discretized into several same volume cells and batches in a series as shown in Figure 1, respectively. Figure 1 depicts the schematic of the MMC model. The algorithm is based on four assumptions as follows [27, 28]: (1) the same temperature and pressure in each cell, (2) no physical dispersion among cells and (3) no capillary force in cells and (4) perfect mixing is taking place in each cell. Based on these assumptions, the calculation in the cell can be transferred to a pure thermodynamic $P / T$ flash calculation and coupled with the Peng-Robinson- (PR-) EOS used in this algorithm.

In this paper, we proposed an MMC method tracking the lengths of all $n_{c}-1$ tie lines by the revised MMC method developed by Zhao et al. [27, 28]. In the modified MMC model, after the cell to cell transfer calculation, we first perform a $P / T$ flash calculation to check if all $n_{c}-1$ key tie lines on the current pressure are located. And then if $n_{c}-1$ key tie lines on a given pressure are found, the calculation at the next increasing pressure should be implemented.

The following steps summarize the detailed procedure for conducting this modified MMC model for estimate MMP:

(1) Specify first the total cell number $\left(N_{c}\right.$, given 1000$)$, cell volume $\left(V_{c}\right.$, given $\left.1.0 \mathrm{~cm}^{3}\right)$, gas/oil ratio (GOR, given 0.3 ), the reservoir temperature, gas and oil compositions, and initial pressure below MMP
(2) The total batch number of gas injection $\left(N_{\mathrm{b}}\right)$ can be calculated by the formula as follows:

$$
N_{b}=\frac{1.2 \times N_{c}}{\mathrm{GOR}}
$$

where the required volume of gas injection is 1.2 times the total volume of slim tube which is a widely used criterion. The amount of gas per batch, GOR $\times V_{c}$, is added into cell 1

(3) It is assumed to have perfect mixing between the injection gas and the fluid in cell reaching thermodynamic equilibrium, so that vapor fraction $(v)$ and the equilibrium compositions of gas and liquid in the cell can be calculated from a $P / T$ flash calculation

(4) The excess volume is moved from cell 1 to cell 2 . The excess fluid transferred from cell 1 to cell 2 is determined by the fractional flow function $\left(f_{\mathrm{g}}\right.$, given 1$)$ as proposed by Zhao et al. And then, the TL is calculated in the step

(5) The excess volume is moved from cell 1 to cell 2 and so on until the last cell is attained

(6) After one batch is completed, a new gas injected into cell 1 is performed, the procedure from steps 3-5 is repeated, and the cell to cell calculations until all $n_{\mathrm{c}}-1$ key tie lines are located. If all key tie lines at the given pressure are located, the calculation at the next increasing pressure should be implemented until TL is equal to zero or less than a specified tolerance of $10^{-6}$

The algorithm flowchart is shown in Figure 2.

When our method is used to calculate the MMPs of real field crude oil samples, the preferred workflow is given 


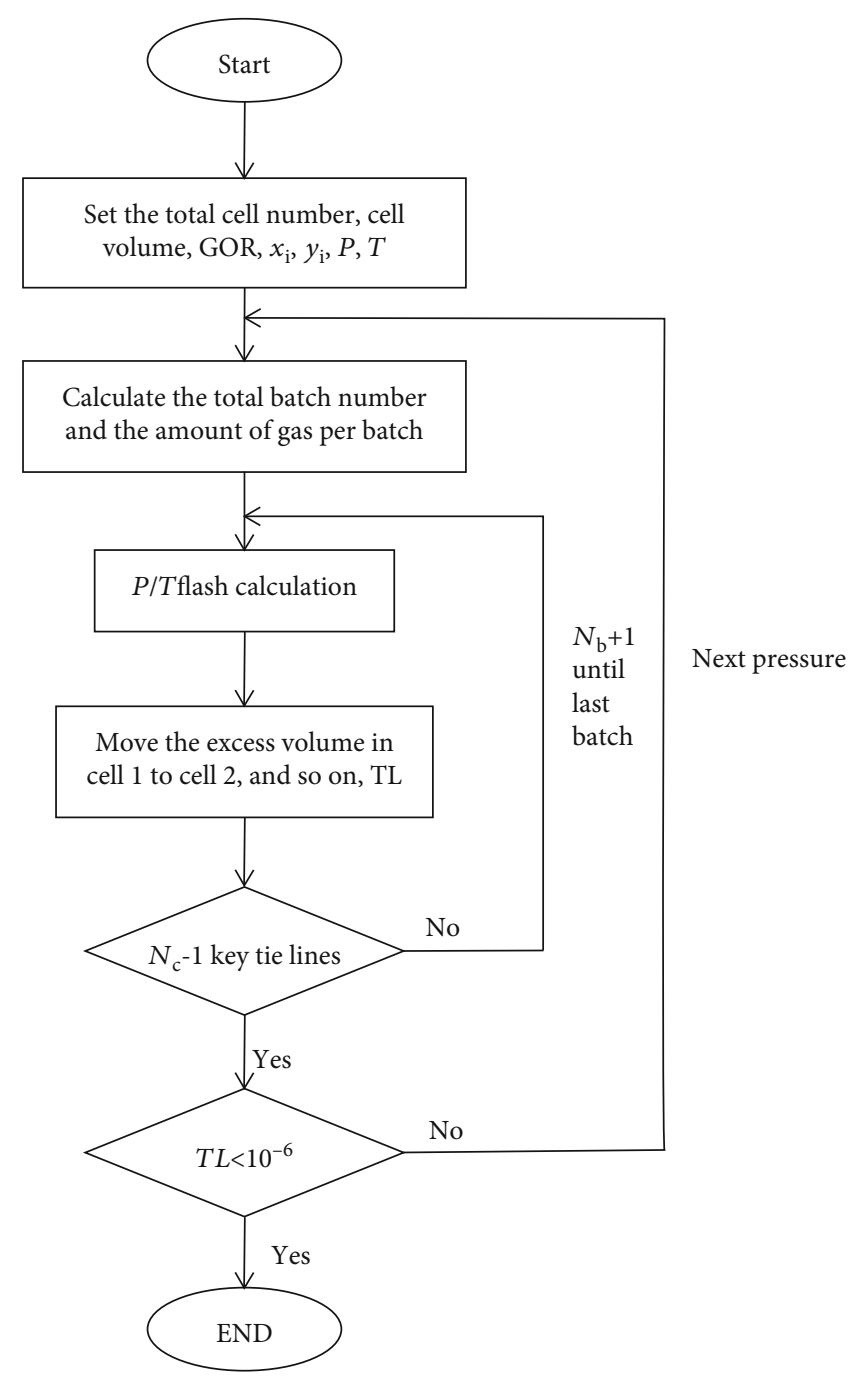

FIGURE 2: Flowsheet diagram of MMP prediction algorithm.

TABLE 1: Oil and gas compositions and PR-EOS properties for Cases $1 \mathrm{a}$ and $1 \mathrm{~b}[16,17,21]$.

\begin{tabular}{lccccccccrrrr}
\hline \multicolumn{4}{c}{ Composition } & \multicolumn{3}{c}{ Properties } & \multicolumn{3}{c}{ Binary interaction parameters } \\
& Oil & Gas & Oil & Gas & $T_{\mathrm{c}}(\mathrm{K})$ & $P_{\mathrm{c}}(\mathrm{MPa})$ & $\omega$ & $\mathrm{C}_{1}$ & $\mathrm{C}_{4}$ & $\mathrm{C}_{10}$ & $\mathrm{CO}_{2}$ \\
\hline $\mathrm{C}_{1}$ & 0.23 & - & 0.2 & 0.2 & 190.59 & 4.604 & 0.0104 & - & - & - \\
$\mathrm{C}_{4}$ & 0.30 & - & 0.15 & - & 425.18 & 3.797 & 0.201 & 0.027 & - & - \\
$\mathrm{C}_{10}$ & 0.45 & - & 0.65 & - & 617.65 & 2.108 & 0.49 & 0.042 & 0.008 & - \\
$\mathrm{CO}_{2}$ & - & 1.0 & - & 0.8 & 304.21 & 7.384 & 0.225 & 0.1 & 0.1257 & 0.0942 & - \\
\hline
\end{tabular}

as follows: in a first step, the $\mathrm{C}_{11}+$ characterization procedure also developed by Neau et al. [29] is suggested to lump the components from TBP (true boiling point) distillation data of crude oil samples; in the second step, the well-established PPR78 model is used to predict the binary interaction parameters for components available in petroleum fluids [30]; finally, based on the above parameters of crude oil and injection gas, the MMP can be calculated by flowsheet diagram of our MMC algorithm as shown in Figure 2.
2.2. Minimum Distance Function. A minimum distance function as the most important step of root-finding techniques is used to find the key tie lines. According to the analytical theory, if two successive tie lines are key ones, they must intersect. In $n$-space, the two lines are described by vector-valued functions as follows:

$$
\begin{aligned}
& Z_{x}=x_{0}+x t, \\
& Z_{y}=y_{0}+y s,
\end{aligned}
$$




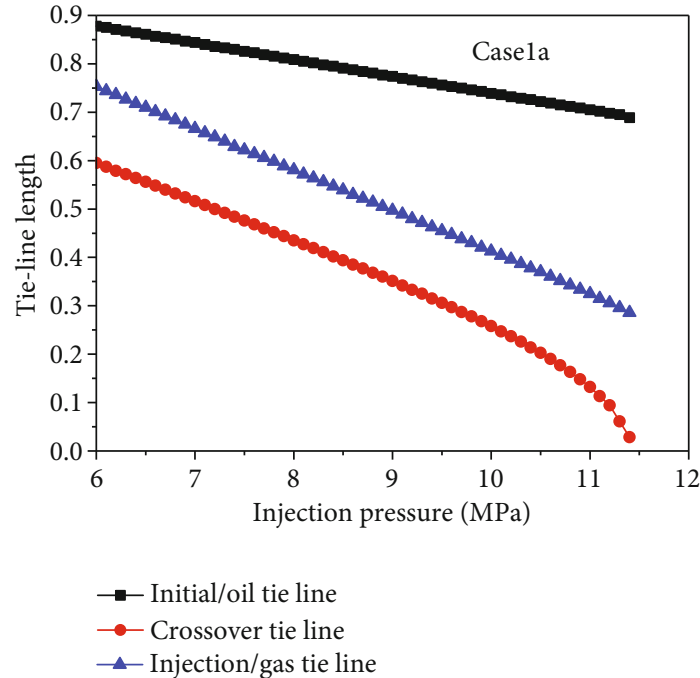

Figure 3: Variation of key tie-line lengths vs. pressure for Case 1a. The MMP was estimated to $11.46 \mathrm{MPa}$ (1662 psia).

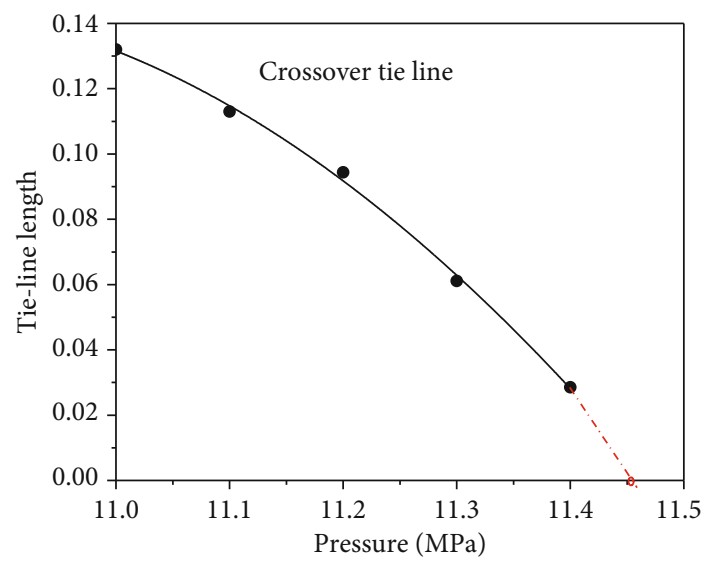

Figure 4: Extrapolation of the length crossover tie line yielded by the MMC method in this work for Case 1a (see Figure 3).

where $Z_{x}, Z_{y}, x_{0}, x, y_{0}$, and $y$ are vectors in $n$-space, and $s$ and $t$ are real parameters.

Thus, the least-squares are used to easily determine the minimum distance between the two lines [31]. If the minimum distance is equal to zero, the two lines must intersect.

\section{Results and Discussion}

In this section, the following examples taken from the published literature have been examined to verify the accuracy of our MMC model determining MMP. The required oil and gas composition of the three cases were taken from the published literature [16-22].

3.1. Case 1: Four-Component System Gas Displacement. We give two cases of four-component systems taken from the published literature: Case 1a and Case 1b. For the two cases, as shown in Table 1 are the composition of oil and gas and PR-EOS properties used [16, 17, 21].

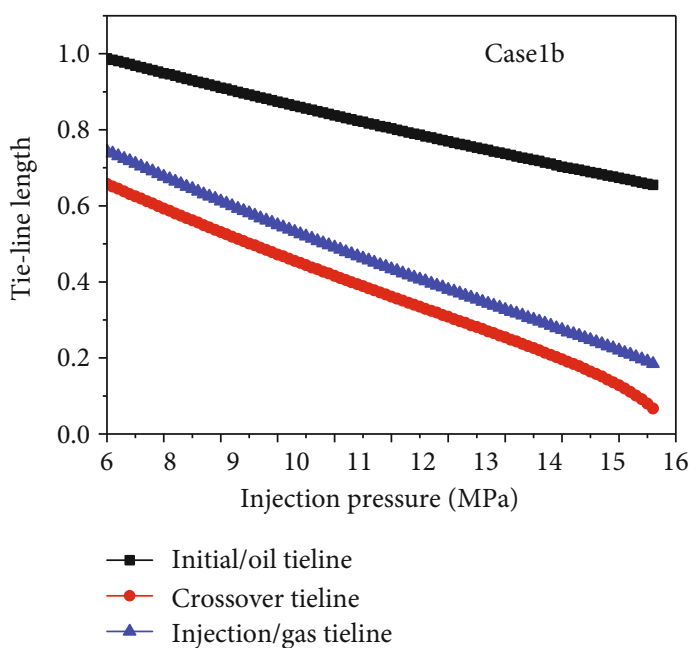

FIGURE 5: Variation of key tie-line lengths vs. pressure for Case $1 \mathrm{~b}$. The MMP was estimated to $15.96 \mathrm{MPa}$ (2314 psia).

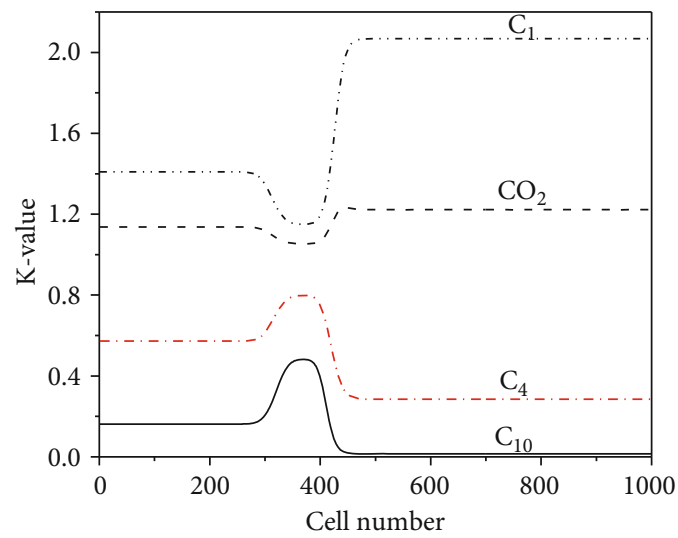

Figure 6: $K$-value profile along the slim tube for Case $1 \mathrm{~b}$ at $15.6 \mathrm{MPa}(2262 \mathrm{psia})$ and $71.1^{\circ} \mathrm{C}\left(160^{\circ} \mathrm{F}\right)$ after all tie lines are developed.

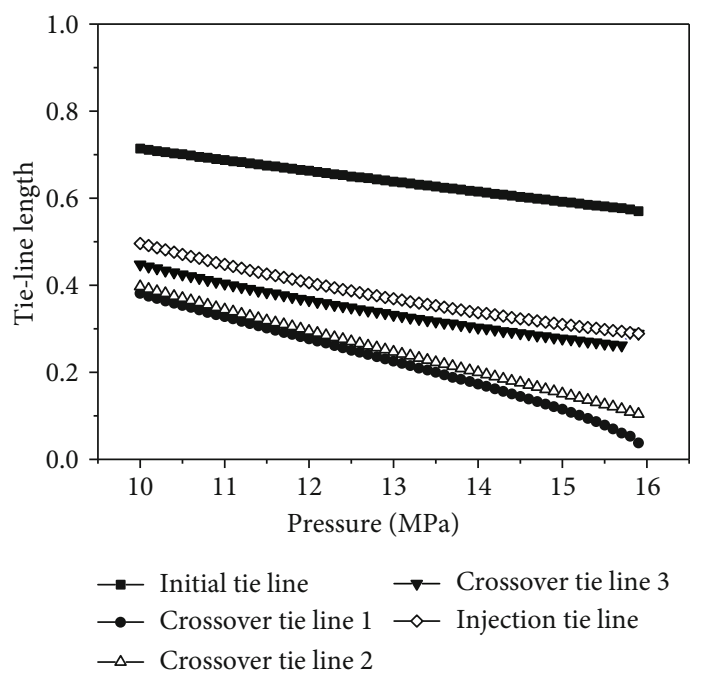

FIgURe 7: Variation of key tie-line lengths vs. pressure for Case 2. The MMP was estimated to $16.02 \mathrm{MPa}$ (2323 psia). 
TABLE 2: Oil and gas compositions and PR-EOS properties for Case 3 [19, 33].

\begin{tabular}{|c|c|c|c|c|c|c|c|}
\hline \multirow[t]{2}{*}{ Component } & \multicolumn{2}{|c|}{ Composition } & \multicolumn{3}{|c|}{ Properties } & \multicolumn{2}{|c|}{$\begin{array}{c}\text { Binary interaction } \\
\text { parameters }\end{array}$} \\
\hline & Oil & Gas & $T_{\mathrm{c}}(\mathrm{K})$ & $P_{\mathrm{c}}(\mathrm{MPa})$ & $\omega$ & $\mathrm{C}_{1}+\mathrm{N}_{2}$ & $\mathrm{C}_{2}+\mathrm{CO}_{2}$ \\
\hline $\mathrm{C}_{1}+\mathrm{N}_{2}$ & 0.341 & 0.646 & 188.22 & 4.561 & 0.0127 & - & - \\
\hline $\mathrm{C}_{2}+\mathrm{CO}_{2}$ & 0.056 & 0.124 & 305.22 & 5.246 & 0.1113 & 0.01511 & - \\
\hline $\mathrm{C}_{3}$ & 0.055 & 0.103 & 369.83 & 4.249 & 0.1454 & 0.00326 & 0.01828 \\
\hline $\mathrm{C}_{4}, \mathrm{~s}$ & 0.059 & 0.089 & 419.22 & 3.745 & 0.1868 & 0.00344 & 0.01708 \\
\hline $\mathrm{C}_{5}, \mathrm{~s}-\mathrm{C}_{6}$ & 0.092 & 0.038 & 487.33 & 3.187 & 0.2693 & 0.00391 & 0.01682 \\
\hline $\mathrm{C}_{7}+(1-2)$ & 0.195 & & 606.72 & 2.598 & 0.3663 & 0.02678 & 0.01682 \\
\hline $\mathrm{C}_{7}+(3-4)$ & 0.155 & & 773.50 & 1.640 & 0.6797 & 0.0434 & 0.01682 \\
\hline $\mathrm{C}_{7}+(5)$ & 0.047 & & 914.28 & 1.091 & 1.0468 & 0.05834 & 0.01682 \\
\hline
\end{tabular}

Case 1a is three-component oil $\left(\mathrm{CH}_{4}, \mathrm{C}_{4}\right.$, and $\left.\mathrm{C}_{10}\right)$ displaced by a pure $\mathrm{CO}_{2}$ gas at a temperature of $71.1^{\circ} \mathrm{C}\left(160^{\circ} \mathrm{F}\right)$. The displacement mechanism of this case study has important characteristics of $\mathrm{CV}$ floods considered to be a challenge. The estimated MMP and the key tie lines for this case using the MMC method are also described by Ahmadi and Johns [21] and Teklu et al. [22].

As previously described, for such a displacement of fourcomponent system, there are three key tie lines: the oil/initial tie line, the gas/injection tie line, and the crossover tie line. Figure 3 shows the variation of key tie-line lengths versus pressure. As shown in Figure 3, the calculation is stopped at a pressure close to the MMP; the crossover tie line 1 would become exactly zero length at the MMP. This is due to the common challenges encountered when one tries to do the flash calculation in the critical region [32]. The MMP is determined by extrapolating through the last five pressure points (shown in Figure 4). For this system, the MMP is estimated to be $11.46 \mathrm{MPa}$ (1662 psia) by our MMC method. The calculated MMP compares well to the result reported in Metcalfe et al. [23] of 11.7 MPa (1700 psia) through Berea sandstone core flooding. The MMP for this case was determined to be $12.03 \mathrm{MPa}$ (1745 psia) by MMC, as reported by Ahmadi and Johns [21].

Case $1 \mathrm{~b}$ is three-component oil $\left(\mathrm{CH}_{4}, \mathrm{C}_{4}\right.$, and $\left.\mathrm{C}_{10}\right)$ displaced by a two-component $\left(\mathrm{CH}_{4}\right.$ and $\left.\mathrm{CO}_{2}\right)$ system as injection gas at a temperature of $71.1^{\circ} \mathrm{C}$. The estimated MMP and the key tie lines for this case applying the MOC are also reported by Orr et al. [17] and Wang and Orr [16].

Figure 5 shows the variation of key tie-line lengths versus pressure. The MMP of this case was found to be $16.20 \mathrm{MPa}$ (2350 psia) and $15.88 \mathrm{MPa}$ (2303 psia) as reported by Jones and Orr [18] and by Ahmadi and Johns [21], respectively. The MMP for this case was estimated to be $15.96 \mathrm{MPa}$ (2314 psia) using the algorithm developed in this study.

Figure 6 gives the $K$-value profile of each component along the slim tube (the cells) at a pressure (15.6 MPa) just slightly lower than MMP (15.96 MPa) estimated by our method. The profile of the $K$-values shows obviously the development of miscibility in the middle of the slim tube, having the feature of a combined CV drive. Moreover, the $K$-values of the crossover tie line is nearest to 1.0 , indicating the crossover tie line controls the displacement miscibility. In

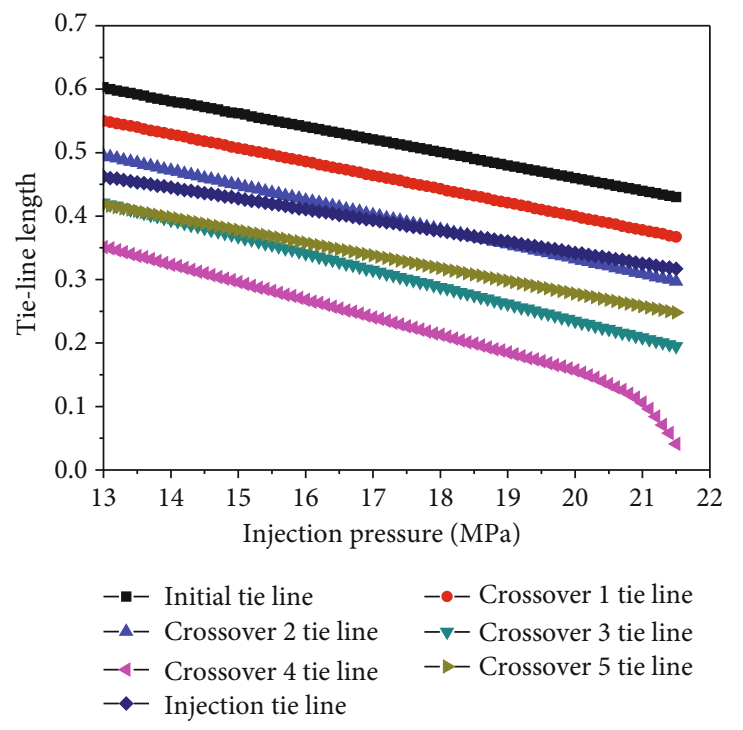

FIGURE 8: Variation of key tie-line lengths vs. pressure for Case 3. The MMP was estimated to $21.72 \mathrm{MPa}$ (3150 psia) by our MMC algorithm.

the process of gas displacement, the condensing drive occurs at slim-tube downstream (the leading edge of the displacement), while the vaporizing drive occurs at slim-tube upstream (the trailing edge of the displacement).

3.2. Case 2: Six-Component System Gas Displacement. Case 2 is six-component oil consisting of $20 \% \mathrm{CH}_{4}, 5 \% \mathrm{CO}_{2}, 5 \%$ $\mathrm{C}_{4} \mathrm{H}_{10}, 40 \% \mathrm{C}_{10} \mathrm{H}_{22}, 10 \% \mathrm{C}_{14} \mathrm{H}_{30}$, and $20 \% \mathrm{C}_{20} \mathrm{H}_{42}$ displaced by pure $\mathrm{CO}_{2}$ as the injection gas. The calculated tie-line length as a function of pressure is illustrated in Figure 7. For this six-component system, there are five key tie lines: the oil/initial tie line, the gas/injection tie line, and three crossover tie lines. And the length of crossover tie line 1 reaches zero at the MMP. The MMP is determined to be 16.02 MPa (2323 psia) by the polynomial extrapolation, which compares well to the estimated MMP of $16.4 \mathrm{MPa}$ (2378 psia) reported in the literature [23].

3.3. Case 3: Rich-Gas Displacement of Eight-Component Oil. Case 3 is eight-component oil displaced by a fivecomponent gas at a temperature of $100^{\circ} \mathrm{C}\left(212^{\circ} \mathrm{F}\right)$, as 
TABLE 3: The comparison of MMP values from this study and the literature.

\begin{tabular}{lccccccc}
\hline \multirow{2}{*}{ Case } & & \multicolumn{2}{c}{ MMP values (MPa) } & \multicolumn{3}{c}{ AD (\%) } \\
& This study (MMC) & MMC & MOC & Slim-tube method & MMC & MOC & Slim-tube method \\
\hline $1 \mathrm{a}$ & 11.46 & 12.03 & 12.06 & 11.70 & 4.74 & 4.98 & 2.05 \\
$1 \mathrm{~b}$ & 15.96 & 15.88 & 16.20 & - & 0.50 & 1.48 & - \\
2 & 16.02 & - & 16.40 & - & - & 2.32 & 3.34 \\
3 & 21.72 & 21.92 & 22.47 & $22.75+/-0.69$ & 0.91 & $4.53+/-3.03$ \\
\hline
\end{tabular}

$\mathrm{AD} \%=100 \times($ MMP of this study $-\mathrm{MMP}$ of other methods)/MMP of other methods.

reported by Hearn and Whitson [33] and Wang [19]. Table 2 lists the oil and gas compositions and the PR-EOS properties.

Figure 8 shows the variation of key tie-line lengths versus pressure from MMC. The estimated MMP from our MMC algorithm is $21.72 \mathrm{MPa}$ (3150 psia) (shown in Figure 8). This is in good agreement with a compositional simulated MMP of $21.92 \mathrm{MPa}$ (3190 psia) and a slim tube-measured MMP of $22.75+/-0.69 \mathrm{MPa}(3300+/-100 \mathrm{psia})$ for this system described by Hearn and Whitson [33], respectively. The MMP of $22.47 \mathrm{MPa}$ (3259 psia) for this system using MOC is reported by Wang [19]. This gas displacement is a combined CV drive because the miscibility of this case is controlled by a crossover tie line.

\section{Comparison of MMP Results}

The values of MMPs obtained in this study have been compared with those taken from the published literature related to MOC (Johns and Orr, Orr et al., and Wang and Orr) [16-18], MMC (Ahmadi and Johns) [21], and slim-tube experimental methods (Metcalfe et al. and Hearn and Whitson) $[23,33]$. Table 3 shows the comparison of MMP values from this study and the literature. As can be seen, MMP values of this study are in good agreement with the results obtained from MOC and MMC and slim-tube experiments, which are found to be reliable within the acceptable accuracy ( $4.53 \%$ to $0.50 \%)$.

\section{Conclusions}

A multiple-mixing-cell (MMC) algorithm has been developed for estimating the MMP by using the PR-EOS coupled with the classical mixing rules. In a comparison of conventional experimental methods and 1D slim-tube simulation, the revised MMC algorithm is simple, robust, and fast. The main conclusions of this study are as follows:

(1) The MMC model can accurately locate all key tie lines for any one of gas floods, regardless of the number of components in the gas-oil systems. Thus, the new MMC algorithm provides a very useful tool for accurately determining the MMP for studying gas injection as a potential EOR method

(2) The results of the MMC algorithm are in excellent agreement with the MMPs and key tie lines from MMC and MOC models and slim-tube experiments taken from the published literature, which are found to be reliable within acceptable accuracy $(4.53 \%$ to $0.50 \%)$. Our MMC algorithm is reliable for whatever displacement types, including combined CV drive

(3) The MMC can be used to reveal the displacement mechanism of gas injection through the $K$-value profile of each component along the slim tube or any one of all key tie-line lengths becoming zero length with increasing pressure

\section{Data Availability}

The data used to support the findings of this study are included in the article.

\section{Conflicts of Interest}

The authors declare that there are no conflicts of interest regarding the publication of this paper.

\section{Acknowledgments}

The project is supported by the Natural Science Foundation of Guangxi Province (Grant numbers: 2016GXNSFBA380 180, 2017GXNSFAA198105, and 2018JJA120001), Scientific Research Foundation of Beibu Gulf University (Grant number: 2016PYGJ09), and High-level Talent Foundation of Beibu Gulf University (Grant number: 18KYQD52).

\section{References}

[1] H. Belhaj, H. Abukhalifeh, and K. Javid, "Miscible oil recovery utilizing $\mathrm{N}_{2}$ and/or $\mathrm{HC}$ gases in $\mathrm{CO}_{2}$ injection," Journal of Petroleum Science and Engineering, vol. 111, pp. 144-152, 2013.

[2] Y. Asswd, A. Kantzas, and P. Pereira Almao, "Numerical modelling of cyclic $\mathrm{CO}_{2}$ injection in unconventional tight oil resources; trivial effects of heterogeneity and hysteresis in Bakken formation," Fuel, vol. 236, pp. 1512-1528, 2019.

[3] T. Wan and Z. Mu, "The use of numerical simulation to investigate the enhanced eagle ford shale gas condensate well recovery using cyclic $\mathrm{CO}_{2}$ injection method with nano-pore effect," Fuel, vol. 233, pp. 123-132, 2018.

[4] H. L. Zhao, Y. W. Chang, and S. L. Feng, "Oil recovery and CO2storage in CO2flooding," Petroleum Science and Technology, vol. 34, no. 13, pp. 1151-1156, 2016.

[5] S. Bender and S. Akin, "Flue gas injection for EOR and sequestration: case study," Journal of Petroleum Science \& Engineering, vol. 157, pp. 1033-1045, 2017. 
[6] A. M. Elsharkawy, F. H. Poettmann, and R. L. Christiansen, "Measuring $\mathrm{CO}_{2}$ minimum miscibility pressures: slim-tube or rising-bubble method?," Energy \& Fuels, vol. 10, no. 2, pp. 443-449, 1996.

[7] A. M. Elsharkawy, F. H. Poettmann, and R. L. Christiansen, "Measuring minimum miscibility pressure: slim-tube or rising bubble method?," in SPE/DOE Enhanced Oil Recovery Symposium, Tulsa, Oklahoma, April 1992.

[8] H. Shojaei, R. Rastegar Moghadam, and K. Jessen, "Experimental and modeling study of multicontact miscible displacements," in SPE Improved Oil Recovery Symposium, Tulsa, Oklahoma, April 2012.

[9] M. Nobakht, S. Moghadam, and Y. Gu, "Determination of CO2Minimum miscibility pressure from measured and predicted equilibrium interfacial tensions," Industrial and Engineering Chemistry Research, vol. 47, no. 22, pp. 8918-8925, 2008.

[10] F. M. Orr and K. Jessen, "An analysis of the vanishing interfacial tension technique for determination of minimum miscibility pressure," Fluid Phase Equilibria, vol. 255, no. 2, pp. 99-109, 2007.

[11] K. Zhang, N. Jia, F. Zeng, S. Li, and L. Liu, “A review of experimental methods for determining the Oil-Gas minimum miscibility pressures," Journal of Petroleum Science and Engineering, vol. 183, p. 106366, 2019.

[12] C. Liao, X. Liao, J. Chen, H. Ye, X. Chen, and H. Wang, "Correlations of minimum miscibility pressure for pure and impure $\mathrm{CO}_{2}$ in low permeability oil reservoir," Journal of the Energy Institute, vol. 87, no. 3, pp. 208-214, 2014.

[13] A. K. Moghaddam and A. H. S. Dehaghani, "Modeling of asphaltene precipitation in calculation of minimum miscibility pressure," Industrial and Engineering Chemistry Research, vol. 56, no. 25, pp. 7375-7383, 2017.

[14] R. T. Johns, P. Sah, and R. Solano, "Effect of dispersion on local displacement efficiency for multicomponent enriched-gas floods above the minimum miscibility enrichment," SPE Reservoir Evaluation \& Engineering, vol. 5, no. 1, pp. 4-10, 2002.

[15] L. Høier, Miscibility variations in compositionally grading petroleum reservoirs, Norwegian University of Science and Technology, Trondheim, 1997.

[16] Y. Wang and F. M. Orr Jr., "Analytical calculation of minimum miscibility pressure," Fluid Phase Equilibria, vol. 139, no. 1-2, pp. 101-124, 1997.

[17] F. M. Orr Jr., R. T. Johns, and B. Dindoruk, "Development of miscibility in four-component $\mathrm{CO}_{2}$ floods," SPE Reservoir Evaluation \& Engineering, vol. 8, no. 2, pp. 135-142, 1993.

[18] R. T. Johns and F. M. Orr Jr., "Miscible gas displacement of multicomponent oils," SPE Journal, vol. 1, no. 1, pp. 39-50, 1996.

[19] Y. Wang, Analytical calculation of minimum miscibility pressure, Stanford University, Stanford, California, USA, 1998.

[20] H. Yuan and R. T. Johns, "Simplified method for calculation of minimum miscibility pressure or enrichment," SPE Journal, vol. 10, no. 4, pp. 416-425, 2005.

[21] K. Ahmadi and R. T. Johns, "Multiple mixing-cell method for MMP calculations," in SPE Annual technical conference and exhibition, Denver, Colorado, September 2008.

[22] T. W. Teklu, S. G. Ghedan, R. M. Graves, and X. Yin, "Minimum miscibility pressure determination: modified multiple mixing-cell method," in SPE EOR conference at oil and gas west Asia, Muscat, Oman, April 2012.
[23] R. S. Metcalfe, D. D. Fussell, and J. L. Shelton, "A multicell equilibrium separation model for the study of multiple contact miscibility in rich-gas drives," Society of Petroleum Engineers Journal, vol. 13, no. 3, pp. 147-155, 1973.

[24] J.-N. Jaubert, L. Wolff, E. Neau, and L. Avaullee, “A very simple multiple mixing cell calculation to compute the minimum miscibility pressure whatever the displacement mechanism," Industrial and Engineering Chemistry Research, vol. 37, no. 12, pp. 4854-4859, 1998.

[25] J.-N. Jaubert, L. Arras, E. Neau, and L. Avaullee, "Properly defining the classical vaporizing and condensing mechanisms when a gas is injected into a crude oil," Industrial and Engineering Chemistry Research, vol. 37, no. 12, pp. 4860-4869, 1998.

[26] R. Li and H. Li, "A modified multiple-mixing-cell algorithm for minimum miscibility pressure prediction with the consideration of the asphaltene-precipitation effect," Industrial \& Engineering Chemistry Research, vol. 58, no. 33, pp. 1533215343, 2019.

[27] G. B. Zhao, H. Adidharma, B. Towler, and M. Radosz, "Using a multiple-mixing-cell model to study minimum miscibility pressure controlled by thermodynamic equilibrium tie lines," Industrial and Engineering Chemistry Research, vol. 45, no. 23, pp. 7913-7923, 2006.

[28] G. B. Zhao, F. Yang, B. Towler, and M. Radosz, "A new approach for calculation of minimum miscibility pressure based on a multiple-mixing-cell model," in AIChe Annual Meeting, San Francisco, CA, USA, November 2006.

[29] E. Neau, J. N. Jaubert, and M. Rogalski, "Characterization of heavy oils," Industrial and Engineering Chemistry Research, vol. 32, no. 6, pp. 1196-1203, 1993.

[30] J. -N. Jaubert, R. Privat, and F. Mutellet, "Predicting the phase equilibria of synthetic petroleum fluids with the PPR78 approach," AIChE Journal, vol. 56, no. 12, pp. 3225-3235, 2010.

[31] J. G. Li, "Study on prediction method of minimum miscibility pressure in gas displacement," in 2010 Second International Conference on Computation Intelligence and Nature Computing, Wuhan, China, September 2010.

[32] F. Yang, G. B. Zhao, H. Adidharma, B. Towler, and M. Radosz, "Effect of oxygen on minimum miscibility pressure in carbon dioxide flooding," Industrial and Engineering Chemistry Research, vol. 46, no. 4, pp. 1396-1401, 2007.

[33] C. L. Hearn and C. H. Whitson, "Evaluating miscible and immiscible gas injection in the Safah field Oman," in SPER reservoir Simulation Symposium, San Antonio, Texas, USA, February 1995. 